\title{
STUDY OF ULTRASONOGRAPHIC EVALUATION OF CONGENITAL RENAL ANOMALIES AND THEIR PROGNOSTIC SIGNIFICANCE
}

\author{
Narendra Singh Sengar1, Siddharth Badola², Kshitiz Nath², Lakshika Saini ${ }^{4}$ \\ 1 Professor, Department of Medicine, MLB Medical College, Jhansi. \\ 2Junior Resident, Department of Medicine, MLB Medical College, Jhansi. \\ ${ }^{3}$ Lecturer, Department of Medicine, MLB Medical College, Jhansi. \\ ${ }_{4}^{4}$ BBBS Student, MLB Medical College, Jhansi.
}

\section{ABSTRACT}

\section{BACKGROUND}

Renal abnormalities are the most common disorder seen on ultrasound. Congenital abnormalities of the kidney and urinary tract occur in approximately 3.3-11.1\% of the population and they account for about $50 \%$ of all congenital abnormalities. This study was done to assess the role of ultrasonography in early detection of malformation in foetal urinary tract and their proper management. If these anomalies are not diagnosed by prenatal ultrasound, many of these would manifest later in life as pyelonephritis, obstruction, stone formation, hypertension, or end-stage renal disease (ESRD).

\section{OBJECTIVES}

1. To assess value of ultrasonography in evaluation of congenital renal malformation.

2. To determine the prognosis of ultrasonographically detected antenatal renal anomalies.

3. To counsel the couple in making reproductive decision in case of lethal abnormality.

\section{METHODS}

This study was conducted at MLB Medical College, Jhansi between January 2014 and August 2015. Of the total 4465 deliveries, screening was possible in 3945 (85\%) deliveries. All antenatal women were screened for renal anomalies by skilled sonologist between 20-37 weeks of gestation. All the babies in whom an abnormalities had been detected antenatally underwent repeat ultrasonography at the end of first week of life.

\section{RESULT}

In our study, we found that the prevalence of congenital renal anomalies among pregnant females was $0.63 \%$. Among these anomalies $(n=25)$, unilateral hydronephrosis $(n=14)$ occurs in most of the cases. In case of isolated vesicoureteral reflux ( $n=3)$ grade II and grade III, unilateral reflux is more common and sepsis was prevented by giving early chemoprophylaxis in 2 cases. In case of posterior urethral valve $(n=2)$, bilateral hydronephrosis occurs and early surgical intervention is required when the baby was born. Of the total 5 cases of unilateral empty renal fossa, pelvic kidney was found in 3 cases. In other 2 cases, kidney was in normal location, but in one it was dysplastic and in other there was renal agenesis. Polycystic kidney disease was detected in 3 cases and all of these 3 cases are bilateral. No surgical intervention is required in these cases at the time of birth, but parents counseling is necessary in these cases. One case was found to be of exstrophy of bladder. Early surgery was done, but the baby survived only for 15 days and died due to sepsis.

\section{CONCLUSION}

This study emphasized the role of prenatal ultrasonography in detection of congenital renal anomalies in pregnant females, which is helpful to determine the requirement of early surgical intervention and chemoprophylaxis that certainly improves the outcome of pregnancy.

\section{KEYWORDS}

Prenatal Ultrasonography, Pregnancy, Renal Anomalies.

HOW TO CITE THIS ARTICLE: Sengar NS, Badola S, Nath K, et al. Study of ultrasonographic evaluation of congenital renal anomalies and their prognostic significance. J. Evolution Med. Dent. Sci. 2016;5(52):3434-3439, DOI: 10.14260/jemds/2016/793

\section{INTRODUCTION}

Renal abnormalities are the most common disorder seen on ultrasound and due to advances in imaging technology, few of any significance are missed. Congenital abnormalities of the kidney are a leading cause of end-stage renal disease (ESRD)

Financial or Other, Competing Interest: None.

Submission 12-05-2016, Peer Review 06-06-2016,

Acceptance 13-06-2016, Published 30-06-2016.

Corresponding Author:

Dr. Narendra Singh Sengar,

Professor, Department of Medicine,

MLB Medical College,

Jhansi.

E-mail: narendra.sengar@gmail.com

DOI: $10.14260 /$ jemds $/ 2016 / 793$ in children and also cause subsequent renal problems in adulthood because many renal anomalies predispose the patient to obstruction, which leads to stone formation, infection, hypertension, and renal failure. Imaging plays an important role in early diagnosis and proper management. Ultrasonography (US) is a non-invasive modality and has a major impact on evaluating renal anomalies either prenatally or postnatally.

Familiarity towards the imaging features of renal anomalies and their complications will provide early diagnosis and proper management and will decrease the incidence of ESRD. The kidney is the most common site of congenital abnormalities. 
Some cause no problems, but many result in impaired renal function. Renal malformations are often associated with other congenital defects. This study was done to assess the role of ultrasonography in detection of malformation in foetal urinary tract. If these anomalies are not diagnosed by prenatal ultrasound many of these urologic abnormalities would manifest later in life as pyelonephritis, hypertension, or endstage renal disease. Hence, we conducted this study to ascertain the incidence of antenatally detected renal malformation and its short-term outcome among live born babies.

\section{RENAL ABNORMALITIES}

\section{Defects in Number and Location}

Unilateral renal agenesis occurs in approximately $1 / 1,300$ pregnancies 1 , the majority of which are probably cases of renal aplasia $^{2}$. The difference between both cannot be made by ultrasound. Although, unilateral renal agenesis is mostly isolated and sporadic, it might be part of a genetic syndrome, or occur in association with chromosomal or developmental defects (VACTERL association) and genital abnormalities. If associated anomalies are present, amniocentesis should be offered. On ultrasound examination, the lumbar fossa is empty and the adrenal gland appears elongated ("Lying down adrenal sign"). The amount of amniotic fluid will be normal. Recent follow up studies attribute an increased risk for chronic kidney disease in adulthood in patients with a solitary functioning kidney especially in the presence of ipsilateral abnormalities of the kidney or urinary tract ${ }^{3}$. Clinical follow up is thus recommended.

Bilateral renal agenesis is a lethal condition with an incidence of $1 / 4,000$ pregnancies ${ }^{4}$. Ultrasound features are early anhydramnios from 16 weeks of gestation onwards, absence of bladder filling, and empty lumbar fossae. Renal artery colour Doppler and Magnetic Resonance Imaging (MRI) may be helpful in confirming the diagnosis.

Ectopic kidneys occur in about $1 / 1,000$ pregnancies 5 . They are usually smaller and may be malrotated. The pelvic location is the most common, but horseshoe kidneys, crossed (fused) ectopia and even intrathoracic kidneys have been described. Uncomplicated renal duplication should be considered as a normal variant. However, renal duplication is often associated with ureteral abnormalities and hydronephrosis.

\section{Defects in Renal Size, Structure and Echogenicity}

Kidneys appear hyperechoic if they look brighter than the liver and spleen beyond 17 weeks of pregnancy. Hyperechoic kidneys are normal in premature babies and infants up to 6 months. However, they are an indicator of significant renal pathology in the paediatric population. Foetal hyperechoic kidneys present an aetiological diversity with an outcome that is specific for each of the conditions.

Non-hereditary foetal hyperechoic kidneys can result from various causes such as an obstructive dysplasia, bilateral multicystic kidney disease, nephroblastomatosis, renal vein thrombosis, ischemia, infectious and metabolic diseases, nephrotic syndrome, and aneuploidy. In case of an underlying genetic syndrome and in polycystic kidney disease, the recurrence rate is high.

The presence of hyperechoic enlarged kidneys without associated malformations is most frequently associated with polycystic kidney disease (Both autosomal recessive and dominant). 6 In case of bilateral isolated hyperechogenic kidneys without family history or cysts, the diagnosis of the underlying aetiology and the counselling of the parents on the long-term prognosis may be challenging. Foetuses with very large kidneys and/or severe oligohydramnios are likely to have a poor outcome. With normal amniotic fluid volumes and moderately enlarged kidneys $(<4 S D)$, the probability of survival without significant morbidity in infancy is high (14/17 survivors of whom 9 symptom-free). ${ }^{7}$ The presence of associated malformations should raise the suspicion of an underlying genetic syndrome, frequently showing an autosomal recessive inheritance pattern (e.g. Bardet-Biedl, Meckel-Gruber, Beemer syndromes).

Detailed foetal ultrasound examination, foetal karyotyping, family history, and ultrasound examination of the urinary system in parents are all important in the work up of hyperechoic enlarged kidneys.

Autosomal Recessive Polycystic Kidney Disease (ARPKD) occurs with an incidence of 1 in 20,000 live births. It is most frequently caused by mutation in the PKHD-1 gene, but probably additional genes play a role and is characterized by cystic dilatation of the tubules, predominantly in the medulla. The outer cortex is spared. In addition of this, patients can have biliary dysgenesis and hepatic fibrosis. The ultrasound scans can be normal up to 20 weeks of pregnancy. Kidneys will be markedly enlarged (+4-15 SD) and hyperechoic without (or with reversed) corticomedullary differentiation and with a hypoechoic outer cortical $\mathrm{rim}^{\mathbf{8}}$. In the perinatal form, oligohydramnios as a consequence of renal failure results in lethal pulmonary hypoplasia. Children with the infantile and juvenile types develop chronic renal failure (with need for transplantation in their teens), hepatic fibrosis, and portal hypertension. The recurrence rate is $25 \%$ and if the mutation is known, prenatal diagnosis can be offered.

Autosomal Dominant Polycystic Kidney Disease (ADPKD) has an incidence of 1 in 800 live births. It is inherited as autosomal dominant with a $100 \%$ penetrance. The family history is positive in only half of cases. ADPKD is usually asymptomatic until the age of 30-40 years and is rarely seen in foetal life. The disease is characterized by cysts in both renal cortex and medulla, in the liver, pancreas, and spleen. On prenatal ultrasound, kidneys are usually moderately enlarged (+1-2 SD) with hyperechoic cortex and hypoechoic medulla (persisting corticomedullary differentiation), but other patterns are described including absent or decreased corticomedullary differentiation or totally normal appearance ${ }^{8}$. Cysts may be visible in the third trimester. The amniotic fluid volume is normal.

Multicystic kidney disease (MCKD) is a developmental disorder of the kidney, in which the normal renal parenchyma is replaced by multiple, non-communicating cysts of varying size. The renal outline is difficult to delineate and can be irregular. The incidence is about $1 / 4,300$ pregnancies. In 25$40 \%$, the contralateral kidney will also be abnormal, reflux being the most frequently associated anomaly. ${ }^{9}$

The natural course in utero is variable and the final result is a non-functional kidney. Bilateral multicystic kidney disease occurs in about $10-20 \%$ of cases and is a lethal condition.

Obstructive cystic dysplasia is the most common cause of non-hereditary foetal renal cystic disease and hyperechoic kidneys. Ultrasound features are those of a lower or upper urinary tract obstruction in association with a hyperechoic 
appearance of the renal cortex and eventually the presence of cysts variable in size. Renal size can also vary. Obstructive cystic dysplasia can be unilateral, bilateral, or segmental, but it is usually a progressive lesion. The amount of amniotic fluid is variable and renal function is usually impaired.

Simple renal cysts are rather uncommon in the foetus. They are usually solitary and localized in the upper pole of a normal kidney. There is no association with other malformations and the prognosis is good. A follow up ultrasound is usually recommended to exclude a more diffuse distribution or other cystic renal diseases.

Renal tumours are rarely seen in foetal life. Mesoblastic nephroma, the most frequent tumour, is a benign, mostly large mesenchymal tumour, which appears as a solid or partially cystic mass, commonly associated with polyhydramnios. It has to be differentiated from Wilms tumours, which have a good prognosis. Nephroblastomatosis is characterized by multiple benign nodular lesions and bilateral involvement.

\section{AIMS AND OBJECTIVES}

1. To assess value of ultrasonography in evaluation of congenital renal malformation.

2. To determine the prognosis of ultrasonographically detected antenatal renal anomalies.

3. To counsel the couple in making reproductive decision in case of lethal abnormality.

\section{MATERIALS AND METHODS}

\section{Study Site and Population}

This study was conducted at MLB Medical College, Jhansi between January 2014 and August 2015. Of the total 4465 deliveries, screening was possible in 3945 (85\%) deliveries.

\section{METHODOLOGY}

All antenatal women were screened for renal anomalies by skilled sonologist between 20-37 weeks of gestation. All the babies in whom an abnormalities had been detected antenatally underwent repeat ultrasonography at the end of first week of life.

\section{Inclusion Criteria}

All the pregnant women between 20-37 weeks of gestation attending the gynaecology clinic and admitted in wards of department of Gynaecology in MLB Medical College, Jhansi between Jan 2014 to Aug 2015.

\section{Exclusion Criteria}

Those pregnant women who are not interested to remain in follow up.

\section{OBSERVATION AND RESULTS}

Diagnosis and Outcome of 25 Babies with Renal Abnormality Confirmed Postnatally is as follow

\begin{tabular}{|c|c|c|c|}
\hline \multirow{2}{*}{\multicolumn{2}{|c|}{$\begin{array}{c}\begin{array}{c}\text { Antenatally Detected } \\
\text { Hydronephrosis }(n=14)\end{array} \\
\text { Causes }\end{array}$}} & \multirow{3}{*}{$\begin{array}{c}\text { No. of } \\
\text { Cases }\end{array}$} & \multirow{3}{*}{$\begin{array}{c}\begin{array}{c}\text { Operative } \\
\text { Intervention }\end{array} \\
0 \\
\end{array}$} \\
\hline & & & \\
\hline \multirow{2}{*}{$\begin{array}{l}\text { PUJ } \\
\text { Obstruction } \\
(n=9)\end{array}$} & Unilateral & & \\
\hline & Bilateral & 2 & 2 \\
\hline \multirow{2}{*}{$\begin{array}{l}\text { VUR (grade } \\
\text { II/III) }(n=3)\end{array}$} & Unilateral & 3 & 0 \\
\hline & Bilateral & 0 & 0 \\
\hline \multicolumn{2}{|c|}{$\begin{array}{l}\text { Posterior urethral valve } \\
\qquad(\mathrm{n}=2)\end{array}$} & 2 & 2 \\
\hline
\end{tabular}

Table No. 1 gives the diagnosis and the outcome for babies who had antenatally detected hydronephrosis. The incidence in our study was found to be $0.35 \%$ of all congenital renal anomalies, which is lower as compared to studies of Blyth et al, 1993; Sairam et al, 2001; Gunn et al, 1995; Levi et al, 2003, which showed the incidence of $0.6-4.5 \%$ in a nonselected population. Out of 14 babies in whom the abnormality was detected, 4 babies had or were soon going to have surgical intervention. Out of 14 babies with hydronephrosis, 9 have PUJ obstruction with incidence of $0.23 \%$, which is in concordance of study of Liang et al, 2002 with incidence of $0.20 \%$. Out of the 3 babies $(0.07 \%)$ with vesicoureteric reflux grade II and III disease, 2 were on chemoprophylaxis and one had urinary tract infection. The 2 babies $(0.05 \%)$ were found to have posterior urethral valve, both of them underwent operation.

\begin{tabular}{|c|c|c|c|}
\hline Causes & & $\begin{array}{l}\text { No. of } \\
\text { Cases }\end{array}$ & $\begin{array}{c}\text { Operative } \\
\text { Intervention }\end{array}$ \\
\hline \multirow{3}{*}{$\begin{array}{c}\text { Unilateral } \\
\text { empty renal } \\
\text { fossa (Ectopic) } \\
(\mathrm{n}=5)\end{array}$} & $\begin{array}{l}\text { Pelvic } \\
\text { Kidney }\end{array}$ & 3 & 0 \\
\hline & $\begin{array}{c}\text { Dysplastic } \\
\text { kidney }\end{array}$ & 1 & 0 \\
\hline & $\begin{array}{c}\text { Renal } \\
\text { agenesis }\end{array}$ & 1 & 0 \\
\hline
\end{tabular}

Table No. 2 gives the diagnosis and outcome for babies who had unilateral empty renal fossa. Out of 5 cases $(0.13 \%)$ reported 3 had pelvic kidney one of which is dysplastic. The incidence of ectopic kidney was found to be $0.07 \%$, which is in concordance with previous study done by Yuksel et al, 2004 (0.05-.10\%). In rest two cases, one was dysplastic kidney, but normal in position and other one had renal agenesis.

\begin{tabular}{|c|c|c|c|}
\hline Causes & & $\begin{array}{l}\text { No. of } \\
\text { Cases }\end{array}$ & $\begin{array}{c}\text { Operative } \\
\text { Intervention }\end{array}$ \\
\hline \multirow{2}{*}{$\begin{array}{c}\text { Multicystic } \\
\text { dysplastic } \\
\text { kidney }\end{array}$} & Unilateral & 1 & 0 \\
\hline & Bilateral & 1 & 0 \\
\hline $\begin{array}{l}\text { Exstrophy of } \\
\text { bladder }\end{array}$ & & 1 & 1 \\
\hline
\end{tabular}

Table No. 3 shows 2 babies (0.05\%) with multicystic dysplastic kidney, one had unilateral disease and other had bilateral disease. One patient $(0.025 \%)$ had exstrophy of bladder who undergo immediate operative intervention, but died after 15 days due to severe sepsis.

\begin{tabular}{|c|c|c|c|}
\hline Causes & & $\begin{array}{c}\text { No. of } \\
\text { Cases }\end{array}$ & $\begin{array}{c}\text { Operative } \\
\text { Intervention }\end{array}$ \\
\hline \multirow{2}{*}{$\begin{array}{c}\text { Polycystic } \\
\text { kidney }\end{array}$} & Unilateral & 0 & 0 \\
\cline { 2 - 4 } & Bilateral & 3 & 0 \\
\hline \multicolumn{4}{|c|}{ Table 4 } \\
\hline
\end{tabular}

Table No. 4 shows babies with polycystic kidney disease. The incidence was found to be $0.08 \%$, which is lower as compared to study done by Wilson et al, $2004(0.12 \%)$. Of these 3 babies, all have bilateral disease. In all these babies, no operative intervention was done and parents are advised for family screening and follow up.

\begin{tabular}{|c|c|c|}
\hline Gender & No. of Subjects & Percentage \\
\hline Male & 18 & 72.0 \\
\hline Female & 7 & 28.0 \\
\hline \multicolumn{2}{|c|}{ Table 5 } \\
\hline
\end{tabular}


Table No. 5 shows gender distribution of babies with congenital renal anomalies. Out of 25 babies 18 (72\%) were males and rest 7 (28\%) were female.

\begin{tabular}{|c|c|c|}
\hline Delivery Mode & No. of Subjects & Percentage \\
\hline Normal Vaginal & 9 & 36.0 \\
\hline LSCS & 16 & 64.0 \\
\hline \multicolumn{2}{|c|}{ Table 6: Mode of Delivery (n=25) } \\
\hline
\end{tabular}

Table No. 6 shows mode of delivery of babies with congenital renal anomalies. Out of 25 babies, 9 (36.0\%) were delivered through normal vaginal and rest 16 (64.0\%) were delivered by lower segment caesarean section.

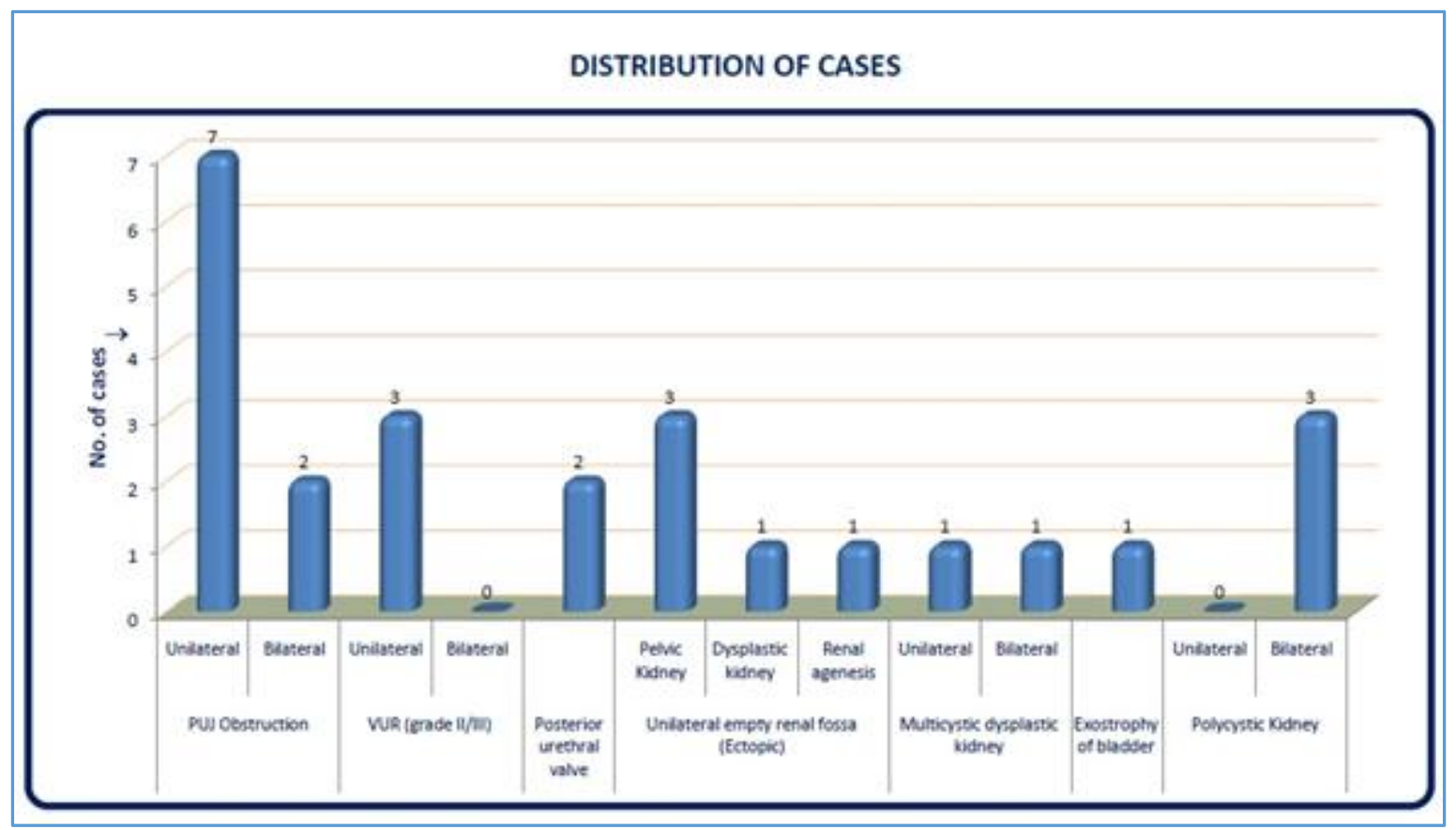

\section{DISCUSSION}

The present study was conducted at MLB Medical College Jhansi from January 2014 to August 2015. The study subjects were all the pregnant women between 20-37 weeks of gestation. Of the total 4465 deliveries, screening was possible in 3945 deliveries (88\%). The renal malformations on antenatal ultrasonography were reported in 28 cases. The mean gestational age at the diagnosis was 33 weeks. 25 babies (89.3\%) of those with abnormal antenatal scan had renal tract malformation confirmed postnatally giving the incidence of $0.63 \%$. Out of these 25 babies, 5 babies (20\%) had bilateral disease and rest were unilateral (80\%). The antenatal scan correctly predicts whether the lesion was unilateral or bilateral. Of the 25 babies, 18 were males (72\%) and 7 were females (28\%). Of these, 16 were born by lower segment caesarean section and 9 by normal vaginal delivery.

In our study, the incidence of renal malformation among live born babies $(0.63 \%)$ is higher as compared to the study conducted by Sanghavi et al $(0.20 \%) .10$ while it is lower than the study conducted in China by Zhang et al (1.67\%).11 at urology department Beijing Children's Hospital. The cause of higher incidence may be due to the difference at the time of presentation in medical setup. Most of the pregnant females were presented in later half of the pregnancy during 30 to 36 week when the detection rate by ultrasonography increases.

We assessed the importance of antenatal diagnosis in terms of definite and probable benefit. If we assume all the babies requiring intervention and chemoprophylaxis benefited from our study then 8 out of 25 i.e. (32\%) were benefited from early diagnosis. Probable benefit is difficult to assess because the natural course and implications of PUJ obstruction and unilateral dysplastic kidney are uncertain. Antenatal diagnosis would probably allow early identification of complications like urinary tract infection, hypertension, and end-stage renal disease. Therefore, additional patients probably benefit. In all the 5 cases, surgical intervention performed at tertiary care paediatric surgery centres. Any potential abnormality detected during pregnancy is a source of severe distress to the parents. Counseling is very much important at this time to advice the patient for making communication with relative specialities when postnatal surgery is performed at distant centre.

There are several studies in the past to estimate the value of USG in diagnosis of congenital renal malformations.

Wiesel A et al (2005) performed a study to evaluate the prevalence of prenatal ultrasound diagnoses for renal anomalies. Standardized data were acquired from 709,030 live births, stillbirths, and induced abortions during the study period of 2.5 years and transmitted for central analysis. Prenatal diagnosis was given in most of all cases with $1 / 3 \mathrm{rd}$ of these pregnancies were terminated.

The highest detection rate was reported for unilateral multicystic dysplastic kidneys with $97 \%$. An early diagnosis was documented for exstrophy of bladder at a mean gestational age of 18.5 weeks. Dilatations of the upper urinary tract were seen late in pregnancy at 28.3 weeks. Terminations of pregnancies were performed in $67 \%$ of the detected bilateral renal agenesis/dysgenesis, but only $4 \%$ of the unilateral multicystic dysplastic renal malformations. In about $1 / 3$ of the cases, renal malformations are within the category 
of associated malformations, which include multiple nonsyndromal malformations, chromosomal aberrations, and non-chromosomal syndromes. Renal malformations were detected in $2 / 3$ of the associated category by the first prenatal ultrasound scan. Detection rates vary due to diverse policies, ethical, and religious background. Countries with no routine ultrasound show the lowest rates in detection and termination of pregnancy. Prenatally detected renal malformations should result in a careful examination for further anomalies. Prenatal ultrasound fulfils the needs of screening examinations and is a good tool in detecting lethal and severe renal malformations ${ }^{12}$.

According to Manish Kumar et al (2012) out of 24,160 deliveries, there were $1.8 \%$ cases with gross congenital anomaly registered in the study period; there were $14.9 \%$ cases with renal anomaly. There were 8 cases, which were lost to follow up and total 55 cases were fully followed up. Diagnosis was done at less than 20 weeks (mean 19 weeks) in 9 cases $(16.4 \%)$, termination of pregnancy was offered in them as the anomaly was severe. The prognosis was said to be poor for cases with gross extra renal anomaly along with the renal anomaly, and for which there was organic renal pathology with loss of renal function suggested by non-visualization of bladder and almost absent liquor. Prognosis was guarded and depended upon the gestational age of presentation in cases, which had obstructive uropathy; prognosis was good in cases, which were mild, unilateral, or which presented late13.

Thomas et al (2001), suggested that prenatal dilatation is not a sensitive indicator of pathology, but increasing dilatation is associated with morbidity and mortality ${ }^{\mathbf{1 4}}$.

Morris et al (2007), concluded that although bladder drainage improves survival, but it may confer a high residual risk of poor postnatal renal function ${ }^{\mathbf{1 5}}$.

Damen-Elias HA et al (2001), chromosomal studies on amniotic fluid should be offered in cases with renal malformation; the incidence of chromosomal abnormality in has reported to be $8-12 \%{ }^{16}$.

\section{SUMMARY}

This study was conducted at MLB Medical College, Jhansi between January 2014 to August 2015 on all pregnant females attending gynaecology clinics and those who are admitted in ward for workup. In our study, we found that the prevalence of congenital renal anomalies among pregnant females was $0.63 \%$. Among these anomalies, unilateral hydronephrosis occurs in most of the cases. In case of isolated vesicoureteral reflux $(n=3)$ grade II and grade III, unilateral reflux is more common and sepsis was prevented by giving early chemoprophylaxis in 2 cases. In case of posterior urethral valve, bilateral hydronephrosis occurs and early surgical intervention is required when the baby was born. Of the total 5 cases of unilateral empty renal fossa, pelvic kidney was found in 3 cases. In other 2 cases, kidney was in normal location, but in one, it was dysplastic, and in other, there was renal agenesis. Polycystic kidney disease was detected in 3 cases and all of these 3 cases are bilateral. No surgical intervention is required in these cases at the time of birth, but parents counseling is necessary in these cases. One case was found to be of exstrophy of bladder. Early surgery was done, but the baby survived only for 15 days and died due to sepsis. The incidence of congenital renal anomaly was found to be greater in male child due to greater incidence of certain anomalies in males e.g. posterior urethral valve is found only in males and polycystic kidney disease is more common in male child.

\section{CONCLUSION}

Hence, this study emphasized the role of prenatal ultrasonography in detection of congenital renal anomalies in pregnant females, which is helpful to determine the requirement of early surgical intervention that certainly improves the outcome of pregnancy. Due to increased awareness about the importance of prenatal ultrasonography, the incidence of detection of congenital renal anomalies increases. The outcome of pregnancy is largely dependent on the counseling of the parents and improved by early intervention either in the form of surgery or chemoprophylaxis (in case of VUR grade II and grade III). The study is also helpful to determine the long-term prognosis of the baby born with renal anomaly. The regular follow up is necessary to prevent the urinary tract infection, hypertension, pyelonephritis, and end-stage renal disease.

\section{REFERENCES}

1. Cascio S, Paran S, Puri P. Associated urological anomalies in children with unilateral renal agenesis. J Urol 1999;162(3 Pt 2):1081-3.

2. Hiraoka M, Tsukahara $H$, Ohshima $Y$, et al. Renal aplasia is the predominant cause of congenital solitary kidneys. Kidney International 2002;61(5):1840-4.

3. Westland R, Schreuder MF, Bokenkamp A, et al. Renal injury in children with a solitary functioning kidney-the KIMONO study. Nephrol Dial Transplant 2011;26(5):1533-41.

4. Potter EL. Bilateral absence of ureters and kidneys: a report of 50 cases. Obstet Gynaecol 1965;25:3-12.

5. Yuksel A, Batukan C. Sonographic findings of foetuses with an empty renal fossa and normal amniotic fluid volume. Foetal diagn Ther 2004;19(6):525-32.

6. Chaumoitre K, Brun M, Cassart M, et al. Differential diagnosis of foetal hyperechogenic cystic kidneys unrelated to renal tract anomalies: a multicenter study. Ultrasound Obstet Gynaecol 2006;28(7):911-7.

7. Tsatsaris V, Gagnadoux MF, Aubry MC, et al. Prenatal diagnosis of bilateral isolated foetal hyperechogenic kidneys. Is it possible to predict long term outcome? BJOG 2002;109(12):1388-93.

8. Brun M, Maugey-Laulom B, Eurin D, et al. Prenatal sonographic patterns in autosomal dominant polycystic kidney disease: a multicenter study. Ultrasound Obstet Gynaecol 2004;24(1):55-61.

9. Schreuder MF, Westland R, Van Wijk JA. Unilateral multicystic dysplastic kidney: a meta-analysis of observational studies on the incidence, associated urinary tract malformations and the contralateral kidney. Nephrol Dial Transplant 2009;24(6):1810-8.

10. Sanghavi KP, Merchant RH, Gondhalekar A, et al. Antenatal diagnosis of congenital renal malformations using ultrasound. J Trop Paediatr 1998;44(4):235-40.

11. Zhang B, Wang $\mathrm{H}$, Sun $\mathrm{N}$, et al. Incidence, diagnosis and treatment of children's congenital abnormalities of the kidney and urinary tract detected in ultrasound screening. Zhonghua Er Ke Za Zhi 2011;49(7):534-8. 
12. Wiesel A, Queisser-Luft A, Clementi M, et al. Prenatal detection of congenital renal malformations by foetal ultrasonographic examination: an analysis of 709,030 births in 12 European countries. Eur J Med Genet 2005;48(2):131-44.

13. Kumar M, Gupta U, Thakur S, et al. Prenatal sonographic evaluation and postnatal outcome of renal anomalies. Indian J Hum Genet 2012;18(1):75-82.

14. Thomas DF. Prenatal diagnosis: does it alter outcome? Prenat Diagn 2001;21(11):1004-11.
15. Morris RK, Malin GL, Khan KS, et al. Antenatal ultrasound to predict postnatal renal function in congenital lower urinary tract obstruction: systematic review to test accuracy. BJOG 2009;116(10):1290-9.

16. Damen-Elias HA, De Jong TP, Stigter RH, et al. Congenital renal tract anomalies: outcome and follow up of 402 cases detected antenatally between 1986 and 2001 . Ultrasound Obstet Gynaecol 2005;25(2):134-43. 